\title{
Analisis Kelayakan Materi Piaud Science Learning Media (PSLM) Berbasis Wonosobo Local Wisdom
}

\author{
Nugroho Prasetya Adi ${ }^{1}$, Vava Imam Agus Faisal ${ }^{2}$ \\ Pendidikan Fisika Universitas Sains Al Qur'an ${ }^{1,}$ PIAUD Universitas Sains Al \\ Qur'an $^{2}$ \\ Email: nugrohoprasetyaadi@gmail.com
}

\begin{abstract}
Abstrak
Masuknya budaya asing melalui berbagai hal mengakibatkan mulai melunturnya pengetahuan generasi muda Indonesia terhadap budaya nya sendiri. Pengenalan budaya sedari dini sudah selayaknya digalakan untuk menanggulangi permasalahan tersebut. Salah satunya melalui bidang pendidikan, dimana peserta didik dikenalkan budayanya melalui proses pembelajaran. Pengenalan budaya melalui pendidikan dapat diberikan salah satunya melalui materi sains, dimana sains merupakan mata pelajaran yang sangat erat kaitannya dengan lingkungan sekitar. Pembelajaran sains jarang dikaitkan dengan nilai kearifan lokal (local wisdom) yang diwariskan leluhur, padahal sains sangat dekat kaitannya dengan lingkungan dan kebudayaan. Tujuan penelitian ini adalah untuk mengembangkan PSLM berbasis wonosobo local wisdom dan mengetahui kelayakan materi pada PSLM Berbasis Wonosobo Local Wisdom berdasarkan penilaian ahli. Metode penelitian yang digunakan adalah $\mathrm{R} \& \mathrm{D}$, dimana produk yang dikembangkan adalah PSLM untuk anak usia dini. Hasil penelitian menunjukkan bahwa telah dihasilkannya PSLM yang layak secara materi dengan kategori sangat baik berdasarkan penilaian ahli.
\end{abstract}

\section{Kata kunci: PSLM, Wonosobo Local Wisdom}

\begin{abstract}
The entry of foreign cultures through various things caused the fading of the knowledge of Indonesia's young generation toward their own culture. The introduction of culture from an early age should be encouraged to overcome these problems. One of them through education, where students are introduced to their culture's through the learning process. The introduction of the culture through education can be given by science material, where science is subject which is very closely related to the surrounding environment. Science learning is rarely associated with the value of local wisdom, even though science is very closely with environment and culture. The purpose of this study is produce PSLM based on wonosobo local wisdom and examine properness of PSLM based on Wonosobo Local Wisdom material. The research method is $R \& D$, where the product produced is PSLM for early childhood. The result showed that PSLM has been produced that is materially feasible with a very good category based on expert judgment.
\end{abstract}

Keywords: PSLM, Wonosobo Local Wisdom

Copyright (c) 2020 nugroho prasetya adi, Vava Imam Agus Faisal 59 


\section{PENDAHULUAN}

Perkembangan teknologi yang sangat pesat dalam beberapa tahun terakhir menimbulkan dampak positif dan negatif dalam beberapa bidang kehidupan. Salah satu dampak positif kemajuan teknologi adalah sebaran budaya Indonesia dan dunia yang sangat cepat yang bisa diakses melalui peralatan elektronik. Sebaran budaya ini secara tidak langsung memberikan pengetahuan bagi generasi muda Indonesia tentang budaya-budaya dari negara lain, sehingga mampu meningkatkan pengetahuannya. Namun disisi lain, sebaran budaya mampu memberikan dampak negatif bagi kelestarian budaya asli Indonesia itu sendiri. Salah satu dampak negatif dari sebaran budaya ini adalah masuknya budaya asing yang mampu melunturkan budaya asli Indonesia. Hal ini menimbulkan kekhawatiran, kerana Indonesia sedang dihadapkan pada lunturnya nilai-nilai kearifan lokal yang mulai perlahan dilupakan oleh penduduknya sendiri, terutama generasi muda sekarang (Mubah, 2011; Suastra \& Luh, 2013). Hasil penelitian menyebutkan bahwa saat ini Indonesia sedang mengalami krisis kebudayaan, dimana ekspansi budaya asing mampu merubah pola pikir dan tindakan masyarakat yang dapat mengakitbatkan hilangnya nilai kemanusiaan, agama, serta budaya nya (Widodo, 2012 \& Mungmachon, 2012). Salah satu langkah yang bisa diambil untuk menanggulangi lunturnya budaya Indonesia adalah mengenalkan budaya asli Indonesia kepada generasi muda sedari dini melalui pendidikan. Pengenalan budaya sedari dini dapat memberikan dampak tumbuhnya kecintaan pada budaya asli Indonesia, mengingat tahapan pertumbuhan pikiran anak usia dini merupakan masa emas dalam tumbuh kembang motorik manusia.

Pendidikan anak usia dini merupakan pendidikan yang ditujukan kepada anak usia 0-6 tahun, dimana pendidikan ini diberikan untuk membantu anak-anak sebelum memasuki pendidikan formal pada tingkat dasar. Pada tahap ini, seorang anak membutuhkan informasi, keterampilan dan stimulasi. Hal ini sejalan dengan teori dari piaget yang menyatakan bahwa anak yang berada di usia 2-7 tahun berada pada tahap pra operasi. Tahap ini anak-anak berusaha memahami simbol dan konsep intuitif. Sehingga pemberian konsep pengetahuan dan keterampilan kepada anak-anak di usia dini sangatlah dianjurkan (Tusifa \& Neneng, 2015). Sejalan dengan Tusifa \& Neneng, (Naili \& Edi, 2014) menyatakan bahwa 50\% anak-anak kemampuan intelektualnya terbentuk pada usia 4-7 tahun, dan mencapai sekitar $80 \%$ pada usia 8 tahun. Rentang usia 4-6 tahun, penyerapan informasi anak sangatlah tinggi, oleh karena itu pada usia ini anak disarankan untuk diberikan pengetahuan \& keterampilan. Proses pendidikan dan pembelajaran pada anak usia dini harus dilakukan untuk memberikan makna, konsep melalui pengalaman nyata (Taufik et al, 2019). Sehingga peran guru sangat penting dalam proses pembelajaran yang berlangsung pada anak usia dini. Salah 1 faktor yang mempengaruhi kualitas pembelajaran adalah bagaimana guru mampu membawa peserta didik masuk ke dalam apa yang dipelajarinya (Andriesen, 2016). Proses pembelajaran di kelas mengandung 5 unsur komunikasi yang harus terpenuhi, yaitu guru, siswa, media pembelajaran, bahan ajar, \& model pembelajaran yang digunakan (Nugroho et al 2019). Sehingga diperlukan media pembelajaran untuk memudahkan guru dalam menyampaikan materi untuk merangsang kemampuan berpikir dan meningkatkan pemahaman peserta didik. 
Media pembelajaran merupakan sarana untuk mentransmisikan atau mengirimkan pesan dan dalam perspektif pembelajaran menyampaikan konten kepada peserta didik untuk mencapai instruksi yang efektif (Ahsan \& Rafaqat, 2016; Saputri et al, 2018). Penggunaan media pembelajaran merupakan cara guru dalam menggunakan alat pengajaran sebagai perantara dalam proses pembelajaran sehingga memudahkan pencapaian tujuan pengajaran (Nugroho \& Yohannes, 2018). Hasil penelitian menyebutkan penggunaan media pembelajaran untuk anak usia dini mampu merangsang anak menjadi lebih aktif dan mampu menghubungkan satu situasi ke situasi lainnya, serta mampu meningkatkan kemampuan kognitifnya (Hendarwati, 2014; Shoffa, 2014; Rohmah \& Waluyo, 2014). Penggunaan media pembelajaran merupakan pengaplikasian dari revolusi industri 4.0, dimana era ini dikenal sebagai disruptive innovation dimana ada 3 hal penting yang harus ada di dalamnya yaitu literasi informasi, literasi media dan literasi ICT (Binkley M. et al, 2012(Nahdi \& Yunitasari, 2020; Yuliastri, Nur Adiyah, ramdhani, 2018)).

Pengenalan budaya Indonesia melalui pendidikan dapat diberikan salah satunya melalui materi sains, dimana sains merupakan mata pelajaran yang sangat erat kaitannya dengan lingkungan. Materi ini cocok diajarkan kepada anak usia dini, kerana mampu mengajarkan tentang cinta lingkungan, dan peka terhadap lingkungan. Selain itu, materi sains juga mampu mengasah motorik anak melalui percobaan kecil yang dapat diberikan kepada anak dan menumbuhkan rasa syukur kepada Sang Pencipta. Trundel menyatakan bahwa pembelajaran sains pada pendidikan anak usia dini memberikan manfaat yang sangat besar untuk berbagai aspek perkembangan anak (Mirawati \& Rini, 2017). Lebih lanjut, (Gross, 2012) menjelaskan pembelajaran sains merupakan proses dari perubahan konseptual dimana anak mengatur ulang pengetahuan yang telah mereka miliki untuk memahami konsep dan proses yang lebih lengkap. Secara tidak langsung, dampak belajar sains adalah menumbuhkan karakter religius, cinta lingkungan, sikap peduli, dan tanggung jawab. Hal ini sejalan dengan program Pemerintah Indonesia, dimana pendidikan karakter harus ditekankan pada jenjang sekolah. Namun realitanya, pembelajaran sains jarang dikaitkan dengan nilai kearifan lokal (local wisdom) yang diwariskan leluhur, padahal sains sangat dekat kaitannya dengan lingkungan dan kebudayaan. Oleh karenanya, diperlukan sebuah pengubung yang mampu mengintegrasikan kedua hal tersebut pada proses pembelajaran, salah satunya adalah dengan memanfaatkan media pembelajaran yang berbasis kearifan lokal.

PIAUD Science Learning Media merupakan media pembelajaran yang disusun dengan konsep sains untuk anak usia dini. Media pembelajaran ini dikembangkan untuk mengenalkan anak usia dini tentang konsep sains, sehingga membentuk karakter anak yang cinta kepada lingkungan dan memiliki rasa syukur kepada Sang Pencipta, serta memiliki kepedulian terhadap sesama. PIAUD Science Learning Media dikembangkan sesuai tingkatan pemikiran anak PAUD dimana bermain merupakan proses pembelajaran yang menarik bagi mereka. Penggunaan local wisdom bertujuan untuk mengenalkan anak pada budaya asli daerahnya, yang dimana akhir-akhir ini sudah mulai dilupakan karena pengaruh budaya lain yang masuk ke Indonesia. Local wisdom merupakan sumber 
pengetahuan yang dinamis, berkembang, dan mempengaruhi masyarakat tertentu, serta terintegrasi dengan alam sekitarnya dan budaya asli mereka ( Local wisdom yang dapat diintegrasikan dengan konsep sains tingkat anak usia dini antara lain gasingan/ permainan tradisional. Gasingan merupakan permainan anak yang terbuat dari kayu yang dimainkan dengan cara melilitkan tali di kepala gasing lalu melemparkan ke tanah. Selain gasingan, ada juga candi yang berada di kawasan Dieng. Bangunan ini didirikan di daerah Dieng Kabupaten Wonosobo. Selain gasingan dan candi, ada sungai serayu yang merupakan salah satu sungai terpanjang di jawa tengah, ada andong/ delman yang dimana di Kabupaten Wonosobo masih banyak dijumpai kendaraan tradisional tersebut, serta anak rambut gimbal yang merupakan local wisdom yang hanya ada di wonosobo terkhusus di daerah dieng.

\section{METODE PENELITIAN}

Penelitian ini menggunakan metode penelitian Research and Development (R\&D). R\&D merupakan sebuah metode penelitian dimana akan menghasilkan produk tertentu (Sugiyono, 2012). Produk yang dikembangkan adalah PIAUD Science Learning Media Berbasis Wonosobo Local Wisdom untuk pendidikan anak usia dini. Subjek penelitian ini adalah guru yang mengajar pada tingkatan paud yang tersebar di Kabupaten Wonosobo. penelitian ini telah dilaksanakan selama 1 bulan dari bulan Maret sampai dengan bulan April 2020. Tempat penelitian adalah sekolah pada tingkatan PAUD yang tersebar di Kabupaten Wonosobo sebanyak 32 sekolah tingkatan PAUD. Instrumen yang digunakan dalam penelitian ini antara lain: lembar validasi materi dan lembar penilaian (kelayakan) materi oleh ahli. Data penelitian yang terkumpul adalah validasi instrumen materi yang dihasilkan dari lembar validasi. Data penilaian guru tentang materi sains dengan lembar penilaian (kelayakan).

Validitas isi ditentukan menggunakan kesepakatan ahli. Kesepakatan ahli diukur dengan menentukan tingkat validitas isi intrumen, dengan menggunakan indeks validitas oleh Aiken. Untuk mengetahui kualitas kelayakan materi, maka data diubah dari skor menjadi data kualitatif (data interval) dengan skala linkert. Adapun acuan pengubahan skor menjadi skala 4 dapat dilihat pada Tabel 1 .

Tabel 1. Acuan Pengubahan Skor menjadi Skala 4

(Mardapi, 2013)

\begin{tabular}{|c|c|c|c|}
\hline No & Rentang Skor & Nilai & Kategori \\
\hline 1 & $X>\bar{X}+1 S B_{x}$ & A & Sangat Baik \\
\hline 2 & $\bar{X}+1 S B_{x}>X \geq \bar{X}$ & B & Baik \\
\hline 3 & $\bar{X}>X \geq \bar{X}-1 S B_{x}$ & C & Cukup \\
\hline 4 & $X<\bar{X}-1 S B_{x}$ & D & Kurang Baik \\
\hline
\end{tabular}

Berdasarkan Tabel 1, maka dapat dilakukan penkonversian dengan skala 4 pada Tabel 2 sebagai berikut: 
Tabel 2. Hasil Konversi Skor menjadi Skala 4

\begin{tabular}{|c|c|c|c|}
\hline No & Rentang Skor & Nilai & Kategori \\
\hline 1 & $X \geq 3,00$ & A & Sangat Baik \\
\hline 2 & $3,00>X \geq 2,51$ & B & Baik \\
\hline 3 & $2,51>X \geq 2,01$ & C & Cukup \\
\hline 4 & $X<2,00$ & D & Kurang Baik \\
\hline
\end{tabular}

Nilai kelayakan materi pada penelitian ini berada pada kategori "Cukup" atau dengan nilai $\mathrm{C}$.

\section{HASIL DAN PEMBAHASAN}

\section{Hasil}

Validasi instrument dilakukan untuk mengetahui apakah instrument yang akan digunakan dalam menilai produk yang dihasilkan sudah valid dab reliabel. Tujuan dari validasi ini agar instrument yang digunakan dapat mengukur apa yang seharusnya diukur.

Instrumen sebelum digunakan untuk melakukan penilaian produk terlebih dahulu dilakukan validasi untuk mengetahui kevalidan dari instrument tersebut. Instrument yang dilakukan validasi adalah instrument pengumpulan data yang terdiri dari lembar penilaian kelayakan materi sains untuk PSLM berbasis wonosobo lokal wisdom. Instrumen disusun melalui Forum Grup Discussion (FGD) sebelum diserahkan kepada ahli untuk divalidasi. Validasi instrumen dilakukan oleh dosen ahli yang mempunyai latar belakang pendidikan anak usia dini. Adapun hasil dari validasi instrumen yang dilakukan oleh ahli disajikan pada Tabel 1. Reliabilitas instrumen didapat dari proses analisis setelah instrumen digunakan langsung oleh 5 orang penilai secara empiris, sehingga data yang dianalisis merupakan data hasil penilaian produk.

Tabel 3. Hasil Validasi Isi dan Reliabilitas Instrumen

\begin{tabular}{|c|l|c|c|c|}
\hline No & \multicolumn{1}{|c|}{ Instrumen } & $\begin{array}{c}\text { Validity } \\
\text { Coef } \\
(\boldsymbol{V})\end{array}$ & Intepretasi & Reliabilitas \\
\hline 1. & $\begin{array}{l}\text { Lembar Penilaian } \\
\text { Materi }\end{array}$ & 1,00 & Valid & Reliabel \\
\hline
\end{tabular}

Berdasarkan Tabel 1, instrumen yang dikembangkan telah valid dan reliabel berdasarkan penilaian dari dosen ahli, sehingga intrumen bisa digunakan untuk melakukan penilaian kelayakan materi.

\section{Hasil Penilaian Kelayakan Materi}

Tahap ini bertujuan untuk mengetahui kelayakan materi sains pada PSLM berbasis wonosobo local wisdom. Data yang dihasilkan pada tahap ini berupa data kuantitatif dan kualitatif. Data kuantitatif yang dihasilkan dari tahap ini berupa 
skor yang diberikan oleh praktisi (guru) dan data kualitatif yang dihasilkan adalah kategori dari data kuantitaif.

Penilaian konten dan konstruk (isi) dari materi sains pada PSLM berbasis wonosobo local wisdom dilakukan oleh guru dari 32 sekolah tingkat pendidikan anak usia dini yang tersebar di wilayah Kabupaten Wonosobo Jawa Tengah. Aspek yang dinilai oleh praktisi adalah aspek materi sains yang disesuaikan dengan tingkat perkembangan anak pada usia dini. Adapun hasil penilaian kelayakan materi oleh praktisi disajikan pada Tabel 2.

Tabel 4. Hasil Penilaian Kelayakan Materi PSLM Berbasis Wonosobo Local Wisdom

\begin{tabular}{|c|l|c|c|}
\hline No & \multicolumn{1}{|c|}{ Aspek } & $\begin{array}{c}\text { Rerata } \\
\text { Skor }\end{array}$ & Kategori \\
\hline 1. & $\begin{array}{l}\text { Kesesuaian materi dengan tingkat } \\
\text { PAUD/PIAUD }\end{array}$ & 3.63 & Sangat Baik \\
\hline 2. & Kejelasan materi yang dipaparkan & 3.34 & Sangat Baik \\
\hline 3. & Keberadaan unsur sains & 3.50 & Sangat Baik \\
\hline 4. & Kebenaran unsur materi & 3.56 & Sangat Baik \\
\hline 5. & $\begin{array}{l}\text { Materi yang disampaikan } \\
\text { mengandung unsur lokal wisdom } \\
\text { wonosobo }\end{array}$ & 3.75 & Sangat Baik \\
\hline 6. & $\begin{array}{l}\text { Kesesuain lokal wisdom wonosobo } \\
\text { dengan materi sains }\end{array}$ & 3.44 & Sangat Baik \\
\hline 7. & $\begin{array}{l}\text { Penggunaan bahasa sesuai dengan } \\
\text { tingkat perkembangan peserta didik }\end{array}$ & 3.31 & Sangat Baik \\
\hline 8. & Ketepatan tata bahasa & 3.38 & Sangat Baik \\
\hline 9. & $\begin{array}{l}\text { Kesesuaian bahasa dengan substansi } \\
\text { pesan }\end{array}$ & 3.56 & Sangat Baik \\
\hline 10. & $\begin{array}{l}\text { Bahasa yang digunakan mampu } \\
\text { menyampaikan pesan kepada peserta } \\
\text { didik }\end{array}$ & 3.63 & Sangat Baik \\
\hline \multicolumn{2}{|c|}{ Skor Rata-rata } & $\mathbf{3 . 5 1}$ & Sangat Baik \\
\hline
\end{tabular}

Berdasarkan hasil penilaian praktisi terhadap kelayakan materi sains pada PSLM berbasis wonosobo local wisdom yang dikembangkan, didapatkan skor rata-rata 3.51 dengan katergori Sangat Baik. sehingga dapat disimpulkan bahwa materi sains pada PSLM berbasis wonosobo local wisdom sangat layak digunakan untuk proses pembelajaran pada tingkatan anak usia dini. Selain memberikan penilaian kelayakan terhadap materi sains pada PSLM berbasis wonosobo local wisdom, praktisi juga memberikan kesimpulan akhir dari penilaiannya. Praktisi memberikan kesimpulan bahwa materi yang dikembangkan pada PSLM berbasis wonosobo local wisdom layak untuk diajarkan pada tingkatan anak usia dini dengan revisi yaitu tata tulis lebih diperhatikan, kolaborasi warna yang digunakan lebih diperhatikan kembali. 


\section{Pembahasan}

Kata media berasal dari kata jamak medium yang berasal dari bahasa latin medius, yang berarti perantara. Media sering digunakan oleh banyak orang dalam kehidupan sehari-hari, termasuk dalam proses belajar mengajar di sekolah. Media dalam proses pembelajaran cenderung diartikan sebagai alat grafis, fotografis untuk menangkat, memproses, dan menyusun kembali informasi visual ataupun verbal yang diterima (Arsyad, 2014; Daryanto 2010). Media pembelajaran dapat digunakan sebagai sumber alternative dalam proses pembelajaran yang berlangsung apabila dirancang dengan baik, sehingga dapat membantu siswa dalam mencerna dan memahami materi pembelajaran (Alimah, 2012; Muhson, 2010). Lebih lanjut media pembelajaran yang menarik juga mampu merangsang perhatian siswa sehingga materi yang disampaikan oleh guru akan dapat dipahami dengan baik oleh siswa (Utari et al, 2014).

PIAUD Science Learning Media merupakan media pembelajaran yang disusun dengan konsep sains untuk anak usia dini. Media pembelajaran ini dikembangkan untuk mengenalkan anak usia dini tentang konsep sains, sehingga membentuk karakter anak yang cinta kepada lingkungan dan memiliki rasa syukur kepada Sang Pencipta, serta memiliki kepedulian terhadap sesama. PIAUD Science Learning Media dikembangkan sesuai tingkatan pemikiran anak PAUD dimana bermain merupakan proses pembelajaran yang menarik bagi mereka. Proses belajar pada anak usia dini harus selaras dengan perkembangan anak, program pendidikan harus disesuaikan dengan anak, bukan anak yang harus menyesuaikan dengan program (Hasdjiandito et al, 2015). PIAUD Science Learning Media dikembangkan sedekat mungkin dengan lingkungan anak, sehingga konsep yang ada dalam media dapat memudahkan anak memahaminya.

PIAUD Science Learning Media dikembangkan berdasarkan local wisdom yang ada di Kabupaten Wonosobo, tujuannya adalah untuk memudahkan peserta didik memahami materi sains dan untuk mengenalkan kebudayaan yang ada di Wonosobo kepada peserta didik. Local wisdom merupakan bagian dari budaya yang berkembang di suatu daerah. Local wisdom jawa misalnya, tentu bagian dari budaya Jawa (Wagiran, 2011). Penggunaan local wisdom bertujuan untuk mengenalkan anak pada budaya asli daerahnya, yang dimana akhir-akhir ini sudah mulai dilupakan karena pengaruh budaya lain yang masuk ke Indonesia. Local wisdom merupakan sumber pengetahuan yang dinamis, berkembang, dan mempengaruhi masyarakat tertentu, serta terintegrasi dengan alam sekitarnya dan budaya asli mereka (Kanhadilok \& Watts, 2013; Demaio, 2011). Kearifan lokal yang dikaji dengan ilmu pengetahuan dapat menumbuhkan pengetahuan kepada peserta didik (Kanhadilok \& Watts, 2013). Di Indonesia, kearifan lokal merupakan filosofi dan pandangan hidup yang diwujudkan dalam beberapa sendi kehidupan seperti tata nilai sosial ekonomi, arsitektur, kesehatan, tata lingkungan dsb (Kemendikbud, 2016).

Berdasarkan definisi local wisdom, dapat disimpulkan bahwa local wisdom dapat diintegrasikan dengan pembelajaran sains yang menekankan pada local wisdom daerah Jawa Tengah terkhusus Wonosobo. Lokal wisdom terdiri dari 6 jenis yaitu permainan tradisional, bangunan tradisional, upacara tradisional, 
kendaraan tradisional, rekreasi dan peninggalan (Kemendikbud, 2016). Local wisdom yang dapat diintegrasikan dengan konsep sains tingkat anak usia dini antara lain gasingan/ permainan tradisional. Gasingan merupakan permainan anak yang terbuat dari kayu yang dimainkan dengan cara melilitkan tali di kepala gasing lalu melemparkan ke tanah. Selain gasingan, ada juga candi yang berada di kawasan Dieng. Bangunan ini didirikan di daerah Dieng Kabupaten Wonosobo. Selain gasingan dan candi, ada sungai serayu yang merupakan salah satu sungai terpanjang di jawa tengah, ada andong/ delman yang dimana di Kabupaten Wonosobo masih banyak dijumpai kendaraan tradisional tersebut, serta anak rambut gimbal yang merupakan local wisdom yang hanya ada di wonosobo terkhusus di daerah dieng

\section{KESIMPULAN}

Penelitian yang dilakukan telah menghasilkan sebuah produk Piaud Science Learning Media (PSLM) berbasis Wonosobo Local Wisdom yang layak untuk digunakan berdasarkan penilaian dosen dan praktisi (guru) dibidangnya. Materi yang dikembangkan pada Piaud Science Learning Media (PSLM) berbasis Wonosobo Local Wisdom telah memenuhi kriteria kelayakan dengan kategori sangat baik berdasarkan penilaian dari 32 praktisi (guru) pendidikan anak usia dini yang tersebar di wilayah Kabupaten Wonosobo. Sehingga PSLM berbasis wonosobo local wisdom dapat digunakan untuk proses pembelajaran pada tingkatan anak usia dini Guru dapat memanfaatkan PSLM berbasis wonosobo local wisdom untuk proses pembelajaran anak usia dini pada materi sains, karena telah materi sains pada PSLM berbasis wonosobo local wisdom telah dilakukan penilaian oleh ahli materi. PSLM berbasis wonosobo local wisdom selain dapat digunakan untuk proses pembelajaran sains, juga dapat digunakan untuk mengenalkan budaya wonosobo kepada peserta didik, sehingga peserta didik mampu mengenali budaya nya.

\section{UCAPAN TERIMAKASIH}

Penelitian ini dilaksanakan melalui program hibah Penelitian Dosen Pemula (PDP) yang diberikan melalui Pendidikan Tinggi (Dikti) Kementerian Pendidikan dan Kebudayaan (Kemendikbud). Oleh Karena itu, peneliti mengucapkan terima kasih kepada pihak yang terkait di dalam Kementerian serta Lembaga Penelitian, Penerbitan, dan Pengabdian Masyarakat (LP3M) Universitas Sains Al Qur'an sehingga penulis bisa mengajukan proposal dan mendapatkan hibah penelitian ini.

\section{DAFTAR PUSTAKA}

Adi, N.P \& Yohannes K. 2018. Meningkatkan Higher Order Thinking Skill Dan Sikap Terbuka Melalui Media Pembelajaran Android. Journal of Komodo. Vol (1) No (1), 79-94.

Adi, NP et al. 2019. Menumbuhkan Sikap Ilmiah (Kolaborasi, Keterbukaan Diri, dan Tanggung Jawab) Melalui Pembelajaran Konstektual. Spektra: Jurnal Kajian Pendidikan Sains, Vol 5 No 2. DOI: 10.32699/spectra.v5vi2i.98. 140-149. 
Ahsan, A.N \& Rafaqat, A.A. 2018. Use of Media for Effective Instruction its Importance: Some Consideration. Journal of Elementary Education, Vol 18, No 1-2. 35-40.

Andriessen, J. (2006). Arguing to learn. In R. K. Sawyer (Ed.), The Cambridge handbook of the learning argumentive discourse. Discourse Processes, Vol (48) No (1), 26-49.

Arsyad, A. (2014). Media pembelajaran. Jakarta: PT Raja Grafindo Persada.

Binkley, M., et al. (2012). Defining Twenty-First Century Skills. In Assessment and Teaching of 21st Century Skills (hal. 17-66). Springer, Dordrecht.

Daryanto. (2010). Media pembelajaran. Yogyakarta: Gava Media.

Demaio, Alessandro. (2011). Local Wisdom and Health Promotion: Barrier or Catalyst?. Asia-Pacific Journal of Public Health, 23 No (2), 127-132, DOI: $10.1177 / 1010539509339607$.

Gross. C., M. 2012. Science Concepts Young Children Learn Through Water Play. Dimensions of Early Childhood Vol 40, No 2.

Hasjiandito, A. dkk. (2015). Presenting Religious Topics: The Effectiveness of Microsoft Powerpoint. Indonesian Journal of Early Childhood Education Studies. Vol (4) No. (2), 111-115.

Hendarwati, E. 2014. Pemanfaatan Media Dalam Pembelajaran Pengetahuan Sosial Di Taman Kanak-Kanak. Jurnal Pendagogi, Vol (1) No (1), 1-7

Kanhadilok, Peeranut., \& Watts, Mike. (2013). Western Science and Local Thai Wisdom: Using Museum Toys to Develop Bi-Gnosis. Canadian Journal of Science, Mathematics and Technology Education, Vol (13) No (1), 33-48, DOI: 10.1080/14926156.2013.758330.

Kemdikbud. (2016). Analisis Kearifan Lokal Ditinjau Dari Keragaman Budaya. PDSPK Kemdikbud RI

Mirawati \& Rini N. 2017. Meningkatkan Keterampilan Proses Sains Anak Usia Dini Melalui Aktivitas Berkebun. Early Childhood: Jurnal Pendidikan, Vol 1 No 1. 1-15.

Mubah, A. S. (2011). Strategi Meningkatkan Daya Tahan Budaya Lokal dalam Menghadapi Arus Globalisasi. Departemen Hubungan Internasional, Vol (24) No (4), 302-308.

Mungmachon, Roikhwanphut. (2012). Knowledge and Local Wisdom: Community Treasure. International Journal of Humanities and Social Science, Vol (2), 174-181.

Nahdi, K., \& Yunitasari, D. (2020). Jurnal Obsesi : Jurnal Pendidikan Anak Usia Dini Literasi Berbahasa Indonesia Usia Prasekolah: Ancangan Metode Dia Tampan dalam Membaca Permulaan Abstrak. 4(1), 434-441. https://doi.org/10.31004/obsesi.v4i1.372 
Naili, R. \& Edi, W. 2014. Artihmetic Dice Media as Counting Concept Introduction Media in Early Chilhood Setting. Indonesian Journal of Early Childhood Education Studies, Vol 3 No 2. DOI: 10.15294.

Ramdhani, S. (2019). Integrative Thematic Learning Model Based On Local Wisdom For Early Childhood Character. Indonesian Journal of Early Childhood Education Studies, 8(1), 38-45.Rohmah, N., \& Waluyo, E. (2014). Arithmetic Dice Media as Counting Concept Introduction for Early Childhood. Indonesian Journal Of Early Childhood Education Studies, Vol (3) No (2), 127-133. doi:10.152942.9486.

Saputri, D.Y et al. 2018. Integrating Game-based Interactive Media as Instructional Media: Students Response. Journal of Education and Learning, Vol 12 No 4. 638-643. DOI: 10.11591/edulearn.v12i4.8290.

Saurina, N. 2016. Pengembangan Media Pembelajaran Untuk Anak Usia Dini Menggunakan Augmented Reality. Jurnal IPTEK. Vol (20) No (1), 95-108.

Shoffa, S. 2014. Penerapan Media Puzzle Cerdas Untuk Meningkatkan Kemampuan Kognitif Anak Taman Kanak-Kanak Dalam Berhitung. Jurnal Pedagogi, Vol (1) No (1), 8-16.

Suastra I W. \& Luh P. B. Y. (2013). Model Pembelajaran Fisika Untuk Mengembangkan Kreativitas Berpikir dan Karakter Bangsa Berbasis Kearifan Lokal Bali. Jurnal Pendidikan Indonesia, Vol (20 No (2), ISSN: 2303-288

Taufik, A. et al. 2019. Parental Perspective on the Excellence of Computer Learning Media in Early Childhood Education. Jurnal Pendidikan Usia Dini. Vol 13, No 2. DOI: https://doi.org/10.21009/JPUD.132.11. 356-370.

Tusifa, J. \& Neneng, T. 2015. Bead Board Letter Effectiveness for the Introduction of Reading Concept Among Children Aged 5-6. Indonesian Journal of Early Childhood Education Studies, Vol 4 No 1, 46-50. DOI: 10.15294

Wagiran. (2011). Pengembangan Model Pendidikan Kearifan Lokal dalam Mendukung Visi Pembangunan Provinsi Daerah Istimewa Yogyakarta 2020 (Tahun Kedua). Jurnal Penelitian dan Pengembangan, Vol (3), 85100.

Widodo, Johannes. (2012). Urban Environment and Human Behaviour: Learning from History and Local Wisdom. Procedia - Social and Behavioral Sciences, Vol (42), 6 - 11, DOI: 10.10162012.04.161.

Yuliastri, N. A., \& Ramdhani, S. (2018). Pengembangan Pembelajaran Tematik Integratif Untuk Meningkatkan Nilai Karakter Anak Usia Dini. Jurnal Golden Age, 2(01), 44-58. 